\title{
Trauma and Compassion Fatigue in Mental Health Professionals Who Help Refugees in the Middle East
}

\author{
Walid Khalid Abdul-Hamid, MBChB, MRCPsych, PhD* \\ Medical Director and Consultant Psychiatrist, Priory Wellbeing Centre Dubai, United Arab Emirates
}

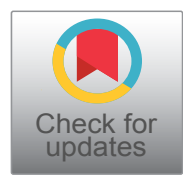

*Corresponding author: Walid Khalid Abdul-Hamid, MBChB, MRCPsych, PhD, Medical Director and Consultant Psychiatrist, Priory Wellbeing Centre Dubai, United Arab Emirates

\begin{abstract}
The impact of working with people and helping them with difficult or traumatic experienced had long been recognized. The problems that affect helping professionals have been termed Compassion Fatigue, Secondary Traumatic Stress, Burnout, Vicarious Traumatization. Since the Iraq War and the Arab Spring, the Middle East has been in constant turmoil that results in traumatisation for the local population and to those trying to help them from local and international mental health care organisations. This article is trying to identify the sign and symptoms of compassion fatigue and the way it could be prevented and cared for in the continuous escalating trauma situation of the Middle East.
\end{abstract}

\section{Introduction}

Similar to how Vietnam's War atrocities triggered the students uprising in Europe and USA in the late 1960s, the atrocities committed during the Iraq war (like Abu Graib prison scandal and the use of prohibited weapons and the complete destruction of the town of Fallujah which were condemned by the whole world at that time) triggered the Arab Spring in the Middle East [1]. This involved military conflict, civil war and terrorism that caused so much trauma in that region [2].

In 2013, I spent a one-year sabbatical leave, from my work as a consultant psychiatrist in the United Kingdom, helping refugees in the Middle East. I tried initially to work at the Syrian refugee camps but later decided to work with the charity Humanitarian Assistance Programme in UK and Ireland (Currently called Trauma Aid UK) to Teach Mental health workers in the Middle East the trauma therapy of EMDR. Meeting many of the mental health professionals who see, hear and treat trauma everyday made me realised the significance of what is called Compassion fatigue or secondary traumatisation. The case histories mentioned in this article were collected from my case treatment supervision of Middle East trainees and because of the difficulties encountered by these trainees, I have collected information on Compassion Fatigue to try to help professionals cope with treating trauma and I am sharing all these materials in this article with all those who work with trauma victims all over the world.

\section{What is Compassion Fatigue}

Compassion Fatigue, that affects helping professionals, was defined by Eric Gentry and his colleagues in 2013 as 'an experience of secondary wounding in caring for trauma survivors that leaves the helper feeling as if they faced the injury on a personal level' [3]. Although the research on this subject started with mental health professionals working with psychological trauma victims, the impact of such problems is now understood to affect professionals like emergency services workers, solicitors, journalists, librarians, nurses, bank workers etc. Even those people volunteering to work with people or animals might feel the negative impact of these experiences [4]. Working with the Middle East traumata not only differ in magnitude but also in complexity. For example 'trauma' have clear and defined terminology in the English language [5], the situation is not as clear in the Arabic translations and the cultural understanding of the term. Sadma which means a sudden blow is used professionally as a translation of Trauma. It is derived from the verb root Sadma which means to hit or to collide. However, on the public level other words are used according to the severity and

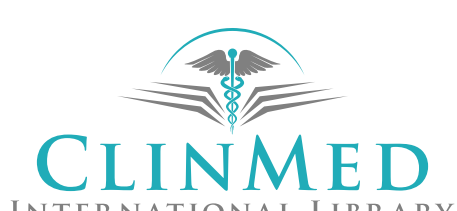

INTERNATIONAL LIBRARY
Citation: Abdul-Hamid WK (2019) Trauma and Compassion Fatigue in Mental Health Professionals Who Help Refugees in the Middle East. Trauma Cases Rev 5:076. doi.org/10.23937/2469-5777/1510076 Accepted: August 20, 2019: Published: August 22, 2019

Copyright: (C) 2019 Abdul-Hamid WK. This is an open-access article distributed under the terms of the Creative Commons Attribution License, which permits unrestricted use, distribution, and reproduction in any medium, provided the original author and source are credited. 
consequences of the trauma. For example in a study of Palestinians living under continuous conflict situation in Gaza, it was found that faji'ah which means tragedy, and musiba which means calamity are also used to described traumatic events. Sadma is used publically to describe painful events that happen suddenly. On the other hand, Faji'ah describes reaction to an extraordinary event, that mainly associates with the loss of a loved one. Musiba describes traumatic events that are persistent and that have long-term consequences [6].

Traumatic events in whatever way they are described can cause disturbance in the function of the body and mind that could be disabling [7]. They can cause varied psychological disorders from the temporary acute stress reaction to anxiety, depression, somatic or body function disturbances to the more severe PTSD and dissociative symptoms. PTSD symptoms have been defined by different clinical classification systems to include defined clusters of symptoms. These include; The re-experiencing of trauma in the form of thoughts, images or emotions, Social withdrawal and numbing of emotions, and increased arousal, irritability and insomnia.

To illustrate the disabling effects of severe trauma exposure we will give a case history of a case presented in my clinical supervision in the Middle East. A civil defence officer in Aleppo heroically saved three of five children from a burning building that was bombarded by regime's forces. He was considered by the community as a hero but he was completely destroyed by the trauma of not being able to save all the children in that building. He withdrew from the community and stopped going to work and became aggressive to his family that he alienated himself from the only remaining social support he had. He was tortured consciously by the images of the dead children day and night that he could not sleep any more.

It is important for people being exposed to trauma to understand that being affected by trauma does not indicate that the person has strong or weak character. Research has shown that the strength of the trauma and the repeated cumulative exposure to trauma can cause post traumatic disorders. This can cause physical and neuro-chemical changes in the brain that cause the disorder [7]. Clinical experience shows that Post Traumatic Stress Disorder (PTSD) appears late as either as recognised mental health problems like depression and anxiety or as not coping which is seen by the person as weakness so $\mathrm{s} / \mathrm{he}$ refuses to seek help. The fear of stigma from professional community cause the person to be in the predicament of being unable to cope but feeling s/he has to stay in control [5].

Trauma treatment and therapy put not only the sufferer but also the professionals in touch with experiences that are 'a stressful event or situation ... of an exceptionally threatening or catastrophic nature, which is likely to cause pervasive distress in almost anyone'
[8]. Such experiences usually challenge our fundamental beliefs in the safety and stability of the world. This fact entail that the treatment of trauma disorders might bring transformation not only to the psyche of the sufferers but also to mental health professionals who try to help these sufferers [9].

In educating the public in disaster or war area, it is important for people who have been exposed to trauma to understand the effects of trauma [3]. Research has shown that trauma can cause post traumatic disorders. This can cause changes in the brain that manifest itself as the PTSD disorder [7]. It has been found that traumatic reaction can happen also as a result of 'emotional contagion'. This mean 'an individual observing - or listening to a story of- another person experience similar emotional responses in parallel to that of person's actual or anticipated emotions' [10]. The American famous psychologist Charles Figley described the concept of Compassion Fatigue (CF) or secondary traumatisation in his book 'Compassion Fatigue: coping with secondary traumatic stress disorder' published in 1995. CF is a common problem amongst mental health professionals treating trauma victims [11].

There is unfortunately a lot of ignorance even amongst mental health professionals who deal indirectly with the traumas of many of their patients or clients [3]. They might often do that with no consideration or giving any thought to the possible effects of this secondary exposure to traumas on their own mental health. This makes it necessary for these professionals to know more about this problem so that they can recognise the effects of secondary exposure to trauma through listening to the history of their patient's problems. The prevention, recognition and treatment of compassion fatigue should become part and parcel of the care process in mental health services.

Moreover, mental health professionals need to be enabled to attend to their own welfare while they are looking after the welfare of their patients [4]. This and only this will enable mental health professionals to be able to help their patients and to sustain a healthy therapeutic relationship with their patients. To illustrate the importance of this I will bring to this paper a case example of a Middle Eastern colleague who suffered this problem while trying to help traumatised Syrian people in one of the many refugee camps:

An Arab mental health professional who live and work in the U.K. Since the beginning of the Syrian revolution he has been using his annual leave to go to refugee camps to help Syrians. He was using not only his psychiatric skills but also, he is a trained trauma therapist using eye movement desensitisation and reprocessing (EMDR). In one of his first visits to a refugee camp in Turkey, he was overwhelmed by the amount of trauma these refugees have suffered to the degree that he 
was seeing them for assessment and EMDR all the time apart from 5 hours sleep he had to have. After five days he started to feel overwhelmed himself. He started feeling distressed and tearful. He started experiencing the traumatic images of the refugees whom he was treating being on his mind all the time when awake and nightmares of these images when asleep. Initially he was hesitant to tell anybody about what he was experiencing thinking that as a psychiatrist with all his experience he should be able to cope, and this will pass. Things started feeling even worst that he started feeling he was lacking any energy or motivation to do his work with the refugees and started becoming angry with them. This is when he decided at last after 10 days to contact his EMDR supervisor. He was advised to return to UK and to receive therapy himself to treat his compassion fatigue.

It is a well-known fact that people who volunteer to work in areas of disaster and danger have what is called 'rescue personality'. This personality is characterised by being; introverted, action seeking, perfectionist in terms of performance, not very social, tend to risk taking, find it difficult to say no, and though highly dedicated to helping others, they can get bored very quickly [12]. The 'rescue personality' was found to be particularly susceptible to compassion fatigue and ultimately to PTSD. This fact makes it necessary that the person carrying out an assignment in a trauma affected area not to work alone and follow through self-awareness and careful monitoring of his thoughts and emotions preferably through supervision of trusted colleagues. In addition and during the humanitarian task the mental health worker need to be aware of their physical needs including sleep and rest, food and fluid intake avoiding self-medication with alcohol or drugs and making sure that they have adequate social and professional support and contact with supervisors and managers to seek advice when needed. Regular exercises are important also to keep physical fitness and help improve mood during the humanitarian assignment [13].

The main symptoms of compassion fatigues in mental health professionals can be summarised by the following [10]:

1. Diminished emotional responses that the person forces him/herself to avoid certain thoughts or feelings that remind them of client'strauma.

2. Avoidance of certain activities or situations because they remind the person of client's frightening experience.

3. Problems with memory in which the person might experience gaps in his/her memory.

4. Social withdrawal and feeling of being isolated from others (even from spouses and partners at times) and feelings that the others are unable to understand his/her highly stressful work experiences with clients.

5. Sleep problems either in the form of having diffi- culty in falling to sleep or problems in maintaining sleep and sleep being disturbed by frightening thoughts, nightmares and troubling dreams similar to those that his/her patients or clients reported to him/her.

6. Agitation associated with outbursts of anger and irritability and triggered by stressful stimuli. There is also startle response that is caused by minor trigger. All this cause the professionals to feel "on edge" about various things and attributing this to their work with certain clients.

7. Flashback of images and events that is similar to those of clients' traumas. There might also be intrusive thoughts after working with some clients with difficult trauma.

8. Conflict about the need of the professional needing to seek helps for his/her traumatic experiences in his/her childhood or adulthood.

9. Sense of danger and being frightened by the things that a patient has said or done.

10. Recall of frightening experiences suddenly and while working with a client.

11. The professional's questioning of his/her concern about the well-being of his clients and feeling trapped by his work.

12. Professional's sense of doom and gloom that associates with his/her work with clients and intense sense of danger felt in working with these clients.

13. Professional's feelings of weakness and tiredness and attributing all this to his working in mental health and not being able to separate his/her work from his/her personal life.

14. Professional's feeling of being depressed about his/her work and the questioning of his/her career choices and his/her effectiveness that leads to thoughts of worthlessness.

15. Professional's questioning of the meaning of life and aspects of his/her spirituality and religious beliefs.

\section{Discussion}

As we mentioned above, it is a well-known fact that people who work or volunteer to work in areas of danger have what is called 'rescue personality'. The 'rescue personality' was found to be particularly susceptible to compassion fatigue and ultimately to PTSD [11]. This fact makes it necessary that the person carrying out an assignment in a trauma affected area not to work alone and follow through self awareness and careful monitoring of his thoughts and emotions preferably through supervision of trusted colleagues [12]. In addition there are two types of psychological awareness that was found to protect against developing psychological disorders following Trauma, these are:

1. Emotional Intelligence (EI): It is the capacity of an 
individual to 'experience, understand, communicate, and manage his/her feeling and those of others [14]. It includes major emotional skills like self awareness \& management and social/relationship awareness \& management [12]. It has been suggested that Traumatic disorders can happen also as a result of 'emotional contagion'. This mean 'an individual observing another person experiencing emotional responses parallel to that person Actual or anticipated emotions' [15]. This is clearly important for people undertaking an assignment in disaster or trauma situation. The level of El was found to be helpful in predicting how individuals respond to traumatic experience. Studies has shown that individuals who have higher El scores reporting fewer psychological symptoms following traumatic experiences $[16,17]$.

2. Cognitive awareness: The ability to recover from the effects of traumatic stress has been found to be related to having positive thoughts and assumptions [14]. So it is very important for people exposed to trauma to be able to develop the habit of reframing the traumatic situations. In reflecting on in what has happened in this situation we need to remind ourselves of any positives that still apply. In thinking about the future focus on steps that you can control. Try to stop yourself from obsessional ruminations on the traumatic events as this might increase your vulnerability [18].

After the Humanitarian assignment it is very important for mental health workers to give themselves the time and the space to recover from the trauma. They should follow their intuition on what they want to talk about regarding the trauma and to whom. They should also make sure that you seek professional psychological or psychiatric help in the following situation [19]:

1. If you feel that there is any risk that you might harm yourself.

2. If you feel so depressed that you are unable to get on with your daily life.

3. If you suffer from outburst of frustration and anger that affect your relationship with others or put them at risk

4. If trauma symptoms described above continue unchanged for several months.

It is a well-known fact that early intervention can help reduce the severity and disability associated with post traumatic problems. The first line treatment of PTSD and other post trauma problems is psychological (i.e. talking therapies) [20]. However, in some cases medication might be needed to help people sleep better or to treat associated depression or anxiety. Furthermore, knowledge and awareness on trauma and its consequences help in the prevention of post traumatic problems.

\section{References}

1. Brigham Robert (2006) Is Iraq another Vietnam. Public Affair, New York.

2. Abdul-Hamid W, Turky J, Hacker Hughes J (2013) Traumabased mental health services for the Arab World. Egyptian Journal of Psychiatry 34: 143-147.

3. Flarity K, Gentry JE, Mesnikoff N (2013) The effectiveness of an educational program on preventing and treating compassion fatigue in emergency nurses. Adv Emerg Nurs J 35: 247-258.

4. Potter P, Pion S, Gentry JE (2015) Compassion fatigue resiliency training: The experience of facilitators. J Contin Educ Nurs 46: 83-88.

5. Brewin CR (2003) Posttraumatic stress disorder: Malady or myth? Yale University Press, New Haven, USA

6. Afana Abdelhamid (2012) Problems in applying diagnostic concepts of trauma reactions and trauma in the Middle East. The Arab Journal of Psychiatry 23: 28-34.

7. New AS, Keegan KA, Charney DS (2007) Psychobiology of resilience to stress. In: Tsuang MT, Stone WS, Lyons MJ, Recognition and prevention of major mental and substance use disorders. American Psychiatric Publishing Inc, Washington, USA.

8. WHO (1992) The ICD-10 classification of mental and behavioural disorders: Clinical descriptions and diagnostic guidelines. WHO, Geneva, Switzerland.

9. Havens Justin (2013) A qualitative study into the experience of EMDR therapists working with UK combat veterans with PTSD. University of Gloucestershire, Gloucestershire.

10. Gentry JE, Baranowsky AB, Dunning K (2002) The Accelerated Recovery Program (ARP) for Compassion fatigue. In: Figley CR, Treating compassion fatigue. Brunner-Routledge, New York, 128.

11. Figley CR (1995) Compassion fatigue as secondary stress disorder. In: Figley CR, Compassion fatigue: coping with secondary traumatic stress disorder in those who treat the traumatised. Routledge, New York.

12. Merlino JP (2011) Rescuing ourselves, self-care in disaster response community. In: Stoddard FJ, Pandya A, Katz CL, Disaster Psychiatry. American Psychiatric Publishing, Inc, Washington DC, USA.

13. Rees $G$ (2013) The trauma factor, reporting on violence and tragedy. In: Fowler-Watt Karen, Allen Stuart, Journalism: New Challenges. Centre for Journalism and Communication Research, Bournemouth, England.

14. Zautra Alex J (2003) Emotions, stress, and health. Oxford University Press, Oxford, New York.

15. Figley CR (2002) Treating compassion fatigue. BrunnerRoutledge, New York.

16. Hunt N, Evans D (2004) Predicting traumatic stress using emotional intelligence. Behav Res Ther 42: 791-798.

17. Matthews G, Zeidner M, Roberts RD (2002) Emotional intelligence: Science and myth. The MIT Press, Cambridge, MA, London, England.

18. https://dartcenter.org/

19. Butler G, Hope T (2007) Managing your mind: The mental fitness guide. Oxford University Press, Oxford, UK.

20. National Institute for Clinical Excellence (2005) Posttraumatic stress disorder, The management of Trauma Reactions in adults and children in primary and secondary care. Gaskell and the British Psychological Society, London. 